\title{
Optimum stochastic modeling for GNSS tropospheric delay estimation in real-time
}

\author{
Tomasz Hadas $^{1}\left[\right.$ [D Felix Norman Teferle ${ }^{2} \cdot$ Kamil Kazmierski $^{1} \cdot$ Pawel Hordyniec $^{1}$ • \\ Jaroslaw Bosy ${ }^{1}$
}

Received: 17 November 2016/Accepted: 11 December 2016/Published online: 23 December 2016

(c) The Author(s) 2016. This article is published with open access at Springerlink.com

\begin{abstract}
In GNSS data processing, the station height, receiver clock and tropospheric delay (ZTD) are highly correlated to each other. Although the zenith hydrostatic delay of the troposphere can be provided with sufficient accuracy, zenith wet delay (ZWD) has to be estimated, which is usually done in a random walk process. Since ZWD temporal variation depends on the water vapor content in the atmosphere, it seems to be reasonable that ZWD constraints in GNSS processing should be geographically and/or time dependent. We propose to take benefit from numerical weather prediction models to define optimum random walk process noise. In the first approach, we used archived VMF1-G data to calculate a grid of yearly and monthly means of the difference of ZWD between two consecutive epochs divided by the root square of the time lapsed, which can be considered as a random walk process noise. Alternatively, we used the Global Forecast System model from National Centres for Environmental Prediction to calculate random walk process noise dynamically in real-time. We performed two representative experimental campaigns with 20 globally distributed International GNSS Service (IGS) stations and compared real-time ZTD estimates with the official ZTD product from the IGS. With both our approaches, we obtained an improvement of up to $10 \%$ in accuracy of the
\end{abstract}

Tomasz Hadas

tomasz.hadas@igig.up.wroc.pl

1 Institute of Geodesy and Geoinformatics, Wroclaw University of Environmental and Life Sciences, Grunwaldzka 53, 50-357 Wrocław, Poland

2 Geophysics Laboratory, University of Luxembourg, 6, Rue Richard Coudenhove-Kalergi, 1359 Luxembourg, Luxembourg
ZTD estimates compared to any uniformly fixed random walk process noise applied for all stations.

Keywords GNSS meteorology · Troposphere · Real-time · PPP · NWP

\section{Introduction}

Troposphere is a major error source in Global Navigation Satellite Systems (GNSS) precise positioning, as the GNSS signal delay depends on the pressure, temperature and water vapor content along the signal path. Furthermore, the delay can be divided into a hydrostatic and a wet component (Mendes 1999). Hydrostatic delay of sufficient accuracy can be provided with empirical models. Such models can be generally divided into two groups. The first group requires surface meteorological data as an input and is based on empirical formula proposed, e.g., by Saastamoinen (1972) and Hopfield (1969), to provide tropospheric delay in zenith direction (ZTD). The second group requires time and approximate coordinates to use average parameters from numerical weather prediction (NWP) models, e.g., GPT2 (Lagler et al. 2013), UNB3 (Leandro et al. 2006). Unfortunately, wet delay depends on the water vapor content that changes rapidly over time and space. There is no model accurate enough for wet delay; therefore, wet delay is usually estimated as an unknown parameter. The wet delays for each GNSS signal in slant direction are mapped into zenith direction using a mapping function, e.g., Niell (1996), UNB3, VMF1 (Böhm et al. 2009). In this way, an epoch-specific parameter ZWD (zenith wet delay) is estimated in the functional model together with other unknown parameters, including receiver coordinates and receiver clock error. 
Although ZWD is treated as an error source in precise positioning, there is great potential of exploiting ZWD for weather and climate monitoring (Bianchi et al. 2016; Guerova et al. 2016). The very dense network of GNSS receivers distributed worldwide becomes a powerful tool for remote sensing of water vapor in the troposphere, called GNSS meteorology (Bevis et al. 1992). Compared to other existing techniques for water vapor monitoring like water vapor radiometers or balloon radio-sounding, GNSS meteorology operates in all weather conditions and provides homogenous products of spatial and temporal resolution higher than any other tropospheric sensing technique (Vedel et al. 2001; Hernández-Pajares et al. 2001). It has already been demonstrated that post-processing of GNSS observations could provide results of accuracy comparable to the measurements of traditional PWV sensors (Pacione and Vespe 2008; Satirapod et al. 2011). ZWD derived from GNSS can be assimilated into NWP models in order to improve forecasting, especially during severe weather conditions (Bennitt and Jupp 2012; Karabatic et al. 2011; Rohm et al. 2014). This was already investigated during EU COST Action 716 (http://www.cost.eu/COST_Actions/ essem/716), and the EUMETNET EIG GNSS water vapor program (E-GVAP, http://egvap.dmi.dk/) was established for monitoring water vapor on a European scale with GNSS in near real-time for the meteorological use (Elgered et al. 2005; Vedel et al. 2013). The reported quality of ZTD estimates from near real-time processing is $3-10 \mathrm{~mm}$ (Pacione et al. 2009; Dousa and Bennitt 2013; Hadas et al. 2013).

Over the last decade, scientific efforts were made to reduce the latency of GNSS-derived tropospheric products. In general, GNSS tropospheric estimates and their timely provision are limited by the accuracy and latency of satellite orbit and clock products. These products are critical for Precise Point Positioning (PPP) technique (Zumberge et al. 1997) that is widely exploited in GNSS meteorology due to its efficiency and flexibility when analyzing GNSS networks with a large number of stations (Yuan et al. 2014; Li et al. 2014). The majority of existing services providing ZTD for meteorology operates in near real-time, using the predicted part of ultra-rapid satellite orbits and clocks. In April 2013, the International GNSS Service (IGS) started Real-Time Service (RTS, http:// www.igs.org/rts/), that provides real-time official products for GPS and unofficial products for GLONASS (Caissy et al. 2012). Individual analysis centers estimate real-time products also for emerging GNSS, including Galileo and BeiDou; however, not all analysis centers provide open access to their products.

The availability of precise GNSS products in real-time opened new possibilities for GNSS meteorology. Dousa et al. (2013) reported standard deviation of ZTDs below
$10 \mathrm{~mm}$, with existing systematic errors of few centimeters, attributed mainly to the incomplete observation model in the software. A decrease in ZTD precision was observed for stations located outside Europe and during the summer months. Ahmed et al. (2016) compared several real-time ZTD estimation software packages. They noticed a significant decrease in the accuracy when ignoring antenna reference point eccentricity, phase center offset and variation. They also noted ZTD errors up to $4 \mathrm{~mm}$ when higher-order terms of ionospheric delay were neglected. On the other hand, the improvement of ZTD estimation from integer ambiguity fixing was at the millimeter level only. Li et al. (2015) reported a significant improvement in ZTD accuracy of about several millimeters when processing multi-GNSS data, rather than $10-20 \mathrm{~mm}$ using singlesystem data. Dousa (2010) demonstrated that most satellite orbit error could be absorbed by the satellite clock errors in PPP, so the orbit error would have a limited effect on PPP derived ZTD. Shi et al. (2015) noticed a strong correlation between the precision of the real-time satellite clock product and the real-time GPS PPP-based ZTD solution. They recommended to choose CNES product rather than IGS product in real-time. Zhu et al. (2010) investigated the effect of selection of elevation-dependent weighting function and propose a cosine square model to benefit from low-elevation observations. This effect was confirmed by Ning (2012), who also noticed that the effect of the mapping function reduces with increasing elevation cutoff angle.

Although a lot of efforts have already been made to optimize real-time GNSS ZWD estimation, a ZWD stochastic modeling aspect remains insufficiently investigated. In post-processing it was commonly accepted to estimate ZWD as a random walk process. Dach et al. (2015) suggest to impose strong relative constraints for the tropospheric parameters to stabilize the system, and Kouba and Heroux (2001) recommended to assign a random walk process noise (RWPN) of $5 \mathrm{~mm} / \sqrt{ } \mathrm{h}$ for ZWD in PPP, and Pacione et al. (2009) applied a ZWD constraint of $20 \mathrm{~mm} /$ $\sqrt{ }$ h. In real-time studies, Lu et al. (2015) reported a RWPN of about $5-10 \mathrm{~mm} / \sqrt{ } \mathrm{h}$, without providing further details. The majority of papers about real-time ZTD or PWV estimation do not provide details about RWPN, mentioning only an epoch-wise estimation of the parameter (e.g., Oliveira et al. 2016) or effective constraining based on an initial empirical test (Dousa et al. 2013).

We investigate the sensitivity of ZWD estimates on the RWPN setting and propose three methods for optimum selection of RWPN for GNSS stations located worldwide. Two methods utilize historical ZWD time series from a NWP to create a global map for optimum ZWD RWPN. The third method takes advantage of NWP short-term forecast to set RWPN according to the expected ZWD 
change in NWP. We performed simulated real-time processing on a representative set of globally distributed stations during summer and winter seasons to validate our approach. We used official IGS ZTD products as a reference.

We first describe the data and products used in this study. Then we describe GNSS processing methodology and methods for RWPN quantification. Thereafter, we present the results of our approaches against a globally fixed RWPN, followed by the conclusions at the end.

\section{Data and products}

This section justifies the selection of experiment time periods. It describes the GNSS data processed and the reference product used in the analysis, as well as the numerical weather prediction models used for RWPN estimation.

\section{Time period}

We selected two data periods for our experiments, each period is one week. The first period, referred to below as summer campaign, is June 4-10 (DoY 155-161), 2013 and is a part of the COST Action ES1206 "Advanced Global Navigation Satellite Systems tropospheric products for monitoring severe weather events and climate" benchmark campaign. The second period, referred to as winter campaign, is November 26 to December 2 (DoY 330-336), 2015. The period selection of the winter campaign was limited due to availability of GNSS and numerical weather prediction (NWP) data and reflects opposite weather conditions to the summer campaign. Both periods were chosen carefully after prior analysis of the time series of IGS final ZTD for selected GNSS stations, in order to focus on challenging conditions.

\section{GNSS data}

Twenty IGS core stations distributed worldwide, in various climatic zones and in a wide range of heights, were selected (Fig. 1). Observations were provided in RINEX files recorded with 30-s interval. Moreover, we used products of IGS RTS recorded in ASCII files with Bundesamt für Kartographie und Geodäsie (BKG) Ntrip Client (BNC) version 2.8 and 2.12 for the summer and winter campaigns. Although both BNC versions record IGS RTS clocks and products in slightly different format, routines were developed to reproduce the IGS RTS stream from both formats.

As reference data for our studies, we used the IGS final ZTD products provided by the US Naval Observatory with

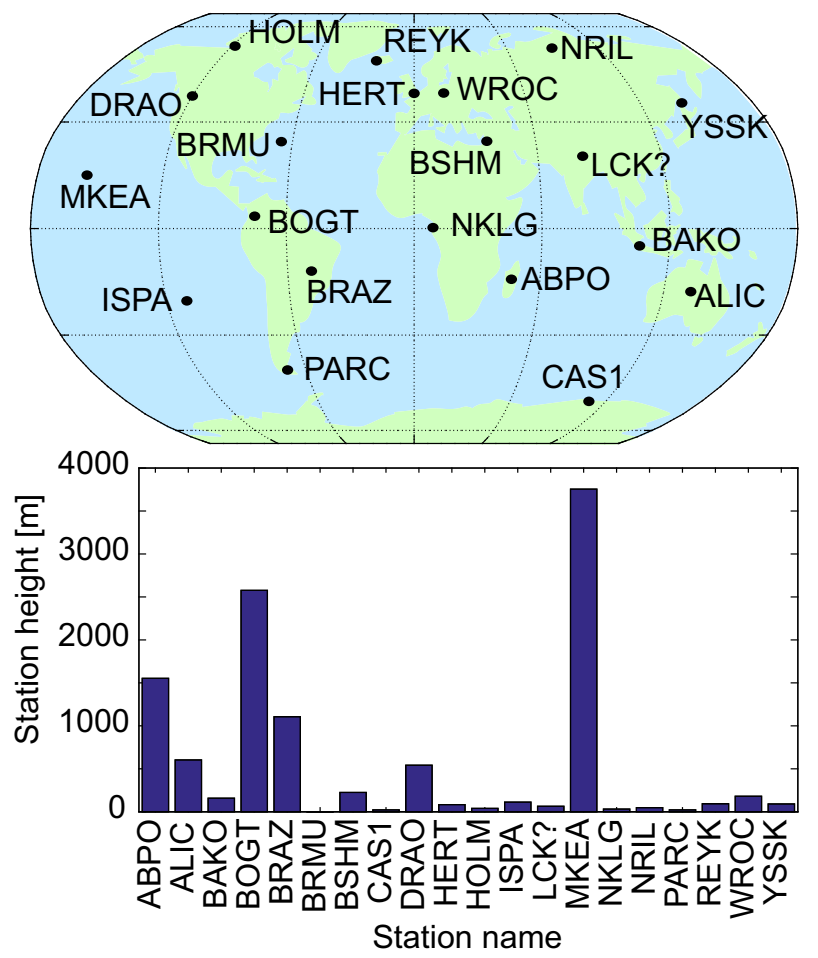

Fig. 1 Location (top) and heights (bottom) of GNSS test stations

5-min interval. The standard deviations of the final ZTDs are between 1 and $2 \mathrm{~mm}$, so this product is a suitable reference since the expected accuracy of the estimated realtime ZTD is one order of magnitude larger.

\section{Numerical weather models}

We used data from two global NWP models, namely the European Centre for Medium-Range Weather Forecasts (ECMWF) and the National Centre for Environmental Prediction (NCEP) Global Forecast System (GFS).

The ECMWF model (http://www.ecmwf.int) provides operational forecast and re-analysis data every $6 \mathrm{~h}$ and is used for the determination of hydrostatic (ZHD) and wet (ZWD) zenith delays together with the coefficients of the Vienna Mapping Functions (VMF1) in a global grid of $2.0^{\circ}$ latitudinal $\times 2.5^{\circ}$ longitudinal spatial resolution. In our study, we used ZHD and ZWD directly from gridded VMF1 final products to obtain global time series for 4 years (2012-2015) of these two parameters, corresponding to surface values. We used ZHD and ZWD time series to estimate offline the yearly or seasonal RWPN grids.

The GFS model (http://www.emc.ncep.noaa.gov/GFS/. php) is the global forecast model of the highest temporal and spatial resolution available today. GFS4 provides forecast in $0.5^{\circ} \times 0.5^{\circ}$ grid. Since May 2016, the GFS4 forecasts are provided hourly, but for the winter campaign 
the forecasts were provided every $3 \mathrm{~h}$. For the summer campaign, the GFS4 was not available, so the studies with GFS4 are limited to the winter campaign only. We used GFS4 short-term forecasts to reproduce ZHD and ZWD with the ray-tracing technique and set RWPN dynamically in real-time processing.

\section{Methodology}

Using the data and products described in the previous section, we estimated RWPN from NWP data and processed GNSS data in several variants. The detailed description of the methodology applied in each step is provided in the following subsections.

\section{GNSS data processing}

For GNSS data processing we used the original, in-house developed GNSS-WARP software (Hadas 2015) for multiGNSS PPP. A standard PPP model is implemented in the software that includes ionospheric-free combination of pseudoranges and carrier phase measurements, and ambiguities are estimated as float values. Observations are processed epoch by epoch, using modified least square adjustment with propagation of the covariance matrix, which is similar to a Kalman filter approach. All precise positioning correction models including satellite antenna offsets, receiver antenna phase center offsets and variations, phase wind-up, solid earth tides, polar tides are implemented according to IERS Convention 2010 and Kouba (2015). In this study, the processing was limited to GPS data only, since only GPS is officially supported by IGS RTS and many other researchers already investigated the impact of multi-GNSS solution on tropospheric estimates. We adopted the strategy of the real-time demonstration campaign of COST ES1206 Action: receiver coordinates were estimated as static parameters, the IGS03 stream from IGS RTS was used, the parameter sampling rate was $30 \mathrm{~s}$, and tropospheric gradients were not estimated. We estimated ambiguities as float static values, reinitializing the ambiguity on occurrence of cycle slips. The receiver clock was estimated as white noise, the elevation cutoff angle was set to $5^{\circ}$, and we applied the inverse of the sine of satellite zenith angle for observation weighting. We removed the hydrostatic delay with VMF-1 derived ZHD and hydrostatic mapping function, while ZWD was estimated as a random walk parameter using VMF-1 wet mapping functions. Finally, we reconstruct ZTD as the sum of ZHD and ZWD at every epoch. Different ZHD and ZWD estimation strategies are implemented in various softwares, so we will analyze RWPN separately for the hydrostatic and wet components.
However, in our real-time ZTD estimates, we only apply wet RWPN.

\section{Random walk process noise}

As already mentioned, it is commonly accepted by the GNSS community to constrain epoch-wise ZWD estimates, usually by estimating ZWD as a random walk parameter. Among various types of random walks, the most appropriate type for ZWD is a one-dimensional Markov process (Bharucha-Reid 1960), due to its simplicity of understanding and implementation. The Markov process is a memory-less stochastic process in which the future value depends only on a present state, not past states (Markov property). Following the theory of the Markov process, the expected translation distance $S$ after $n$ steps, each being of length $\varepsilon$, is expressed by the following formula:

$E\left(\left|S_{n}(\varepsilon)\right|\right)=\varepsilon \sqrt{n}$

Adopting (1) to tropospheric delay $\Delta T$ and replacing the number of steps $n$ with time $t$ and time interval $\delta t$ we can write:

$E\left(\left|\Delta T_{t+\delta t}-\Delta T_{t}\right|\right)=\varepsilon \sqrt{\delta t}$

which means that the expected change in $\Delta T$ after the specific time interval $\delta t$ depends on the interval length and defined translation distance $\varepsilon$, which can be considered as RWPN. If we know two $\Delta T$ values and the interval, we can rearrange (2) in order to estimate RWPN as:

$E(\varepsilon)=\left|\Delta T_{t+\delta t}-\Delta T_{t}\right| / \sqrt{\delta t}$

In case we have a time series of $\Delta T$, we can estimate the mean RWPN as an average value over the entire time series, as well as assess the uncertainty of the RWPN estimate with a standard deviation for all single-epochs RWPN.

\section{Ray-tracing}

Ray-traced ZTDs are derived from 3-hourly forecasts of the GFS model using 4 model cycle per day at $00,06,12$, 18 UTC so that the most up-to-date atmospheric state is always considered to minimize the forecast introduced uncertainty. The total tropospheric delay in zenith direction is simply taken as an integral of refractivity $N$,

$\mathrm{ZTD}=10^{-6} \int_{h_{0}}^{\infty} N(z) \mathrm{d} z$

where $\mathrm{h}_{0}$ is a station height. The ionospheric refraction, as well as aerosols contribution to the computed delays, is 
neglected. The atmospheric refractivity is expressed in terms of pressure $P$, temperature $T$ and water vapor pressure $P_{w}$, following the separation on hydrostatic and nonhydrostatic constituents according to Davis et al. (1985),

$N=k_{1} R_{\mathrm{d}} \rho+k_{2}^{\prime} \frac{P_{\mathrm{w}}}{T}+k_{3} \frac{P_{\mathrm{w}}}{T^{2}}$

where $k$ denotes "best available" empirical coefficients of refractivity given by Rüeger (2002). The new constant equals to $k_{2}^{\prime}=k_{2}-k_{1} R_{\mathrm{d}} / R_{\mathrm{w}}$, with $R_{d}$ and $R_{w}$ being gas constants for dry and wet air, respectively, whereas the total mass density $\rho$ is calculated as a sum of partial densities

$\rho=\rho_{\mathrm{d}}+\rho_{\mathrm{w}}=\frac{\left(P-P_{\mathrm{w}}\right) M_{\mathrm{d}}}{R_{\mathrm{u}} T}+\frac{P_{\mathrm{w}} M_{\mathrm{w}}}{R_{\mathrm{u}} T}$

In this equation, $R_{\mathrm{u}}$ is the universal gas constant, and $M_{\mathrm{d}}$ and $M_{\mathrm{w}}$ are molar masses for dry and wet air, respectively. The vertical resolution of the GFS model is described by 26 isobaric surfaces with an uppermost level that reaches approximately 30 geopotential kilometers. Due to this limitation, a single atmospheric profile above query station coordinates is up-sampled in order to achieve vertical spacing of $10,20,50,100,500 \mathrm{~m}$, respectively, for geometric altitudes between $0-2 \mathrm{~km}, 2-6 \mathrm{~km}, 6-16 \mathrm{~km}$, $16-36 \mathrm{~km}$ and above $36 \mathrm{~km}$ as suggested by Rocken et al. (2001). Hence, the geopotential levels are converted to geometric heights to perform exponential interpolation in the domain of air pressure and water vapor pressure and linearly for temperature. The horizontal interpolation uses 2D Shepard method based on weighted mean averaging accordingly to distance from nearest model nodes. Above the upper limit of the GFS model we apply the US Standard Atmosphere (1976) to provide auxiliary meteorological data up to $86 \mathrm{~km}$.

\section{Experiment variants}

We used the simulated real-time mode of the GNSSWARP software that reconstructs real-time observation and RTS correction streams from RINEX and BNC-derived ASCII files, respectively. It this way we could process the same GNSS data using 4 variants of wet RWPN settings, namely: fixed, yearly, seasonal and dynamic.

In the fixed variant, we applied the same wet RWPN for all test stations. We performed 10 runs of the fixed variant, because we investigated wet RWPN in the range from $1 \mathrm{~mm} / \sqrt{ } \mathrm{h}$ to $10 \mathrm{~mm} / \sqrt{ } \mathrm{h}$ in steps of $1 \mathrm{~mm} / \sqrt{ } \mathrm{h}$. The purpose of this variant was to investigate whether a global optimum value for wet RWPN exists or not.

In the yearly variant, we used (3) with ZHD and ZWD time series from VMF-1 in order to estimate global grids of mean hydrostatic and wet RWPN. We estimated yearly grids for each year between 2012 and 2015. For each campaign, we used a grid for the year prior to the processing time, to reflect the case of real-time processing. In the seasonal variant, we estimated time series of mean hydrostatic and wet RWPN with a 6-h interval. We used 30 -day sliding window covering \pm 15 days of the corresponding time one year before the current processing time. In both yearly and seasonal variants, we interpolated RWPNs for each station using the 4 nearest grid points and inverse of squared distance weighting, following the VMF1 interpolation approach. The yearly variant took into account the global variability of RWPN, while the seasonal variant also took into account the variability over seasons. The reason why we also calculated hydrostatic RWPN grids is related to the different tropospheric estimation strategies that might be implemented in other software. In case ZTD, not ZWD, is estimated directly, the ZTD RWPN can be calculated as a root square of the sum of squared hydrostatic and wet RWPNs.

In the dynamic variant we took advantage of the GFS4 model and ray-tracing technique. Every $3 \mathrm{~h}$ we estimated new wet RWPNs using (3) and two consecutive epochs of the shortest available GFS4 forecasts. This variant is similar to the seasonal variant, as it also takes into account the temporal variability of RWPN. The advantage is the use of current rather than historical data and a two times higher temporal resolution. Although this variant is the only one that requires additional computational power to perform ray-tracing, it was already shown by Zus et al. (2014) and Wilgan (2015) that the delivery of NWP-troposphere products in real-time is possible.

\section{Results}

We analyzed the processing results paying particular attention to RWPN differences among experiment variants and compared ZTD estimates with the reference product to verify the proposed methods of RWPN quantification.

\section{Hydrostatic and wet RWPN grids}

Yearly mean hydrostatic and wet RWPN grids are presented in Fig. 2. We noticed both hydrostatic and wet RWPN to be geographically dependent. Hydrostatic RWPN varies from $0.3 \mathrm{~mm} / \sqrt{\mathrm{h}}$ around poles to $4.1 \mathrm{~mm} /$ $\sqrt{ } \mathrm{h}$ for ocean areas along $60^{\circ} \mathrm{S}$ latitude. The mean hydrostatic RWPN value is $1.8 \mathrm{~mm} / \sqrt{ } \mathrm{h}$ with a standard deviation of $0.7 \mathrm{~mm} / \sqrt{ } \mathrm{h}$. In all hydrostatic grids, we noticed an occurrence of regular cycles along the equator, shifted by $90^{\circ}$. This corresponds to the temporal resolution of the ECMWF model. Although the hydrostatic RWPN differences along the tropical region are smaller than $1 \mathrm{~mm} / \sqrt{ } \mathrm{h}$, 

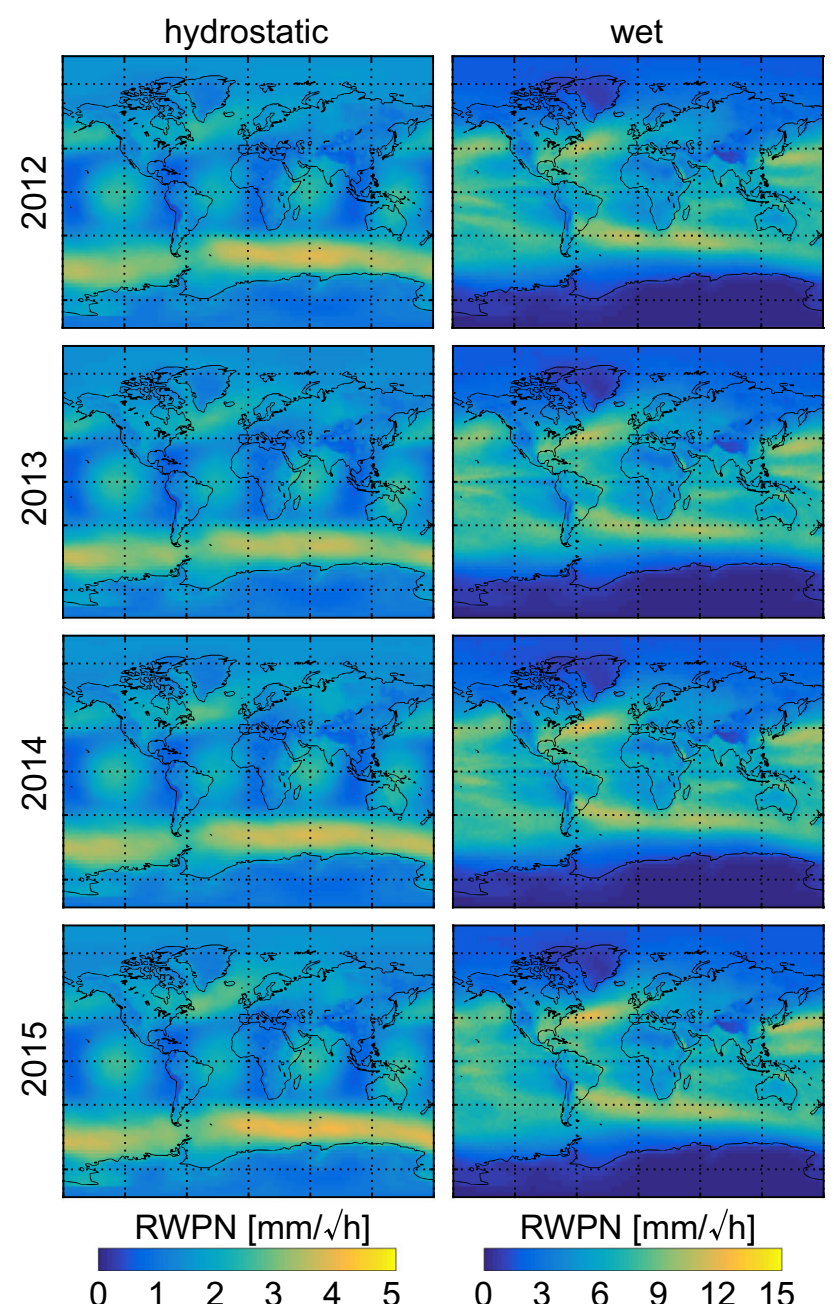
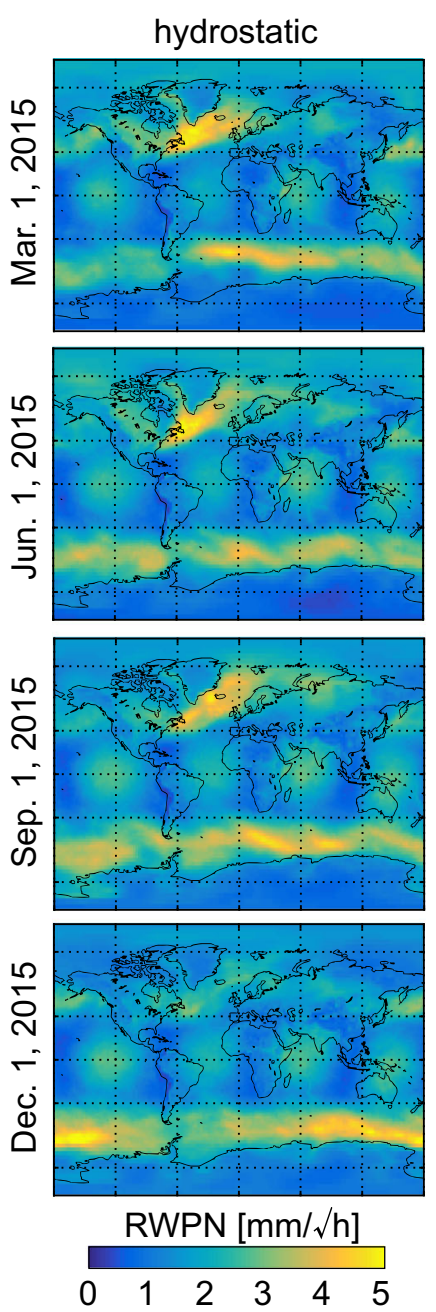
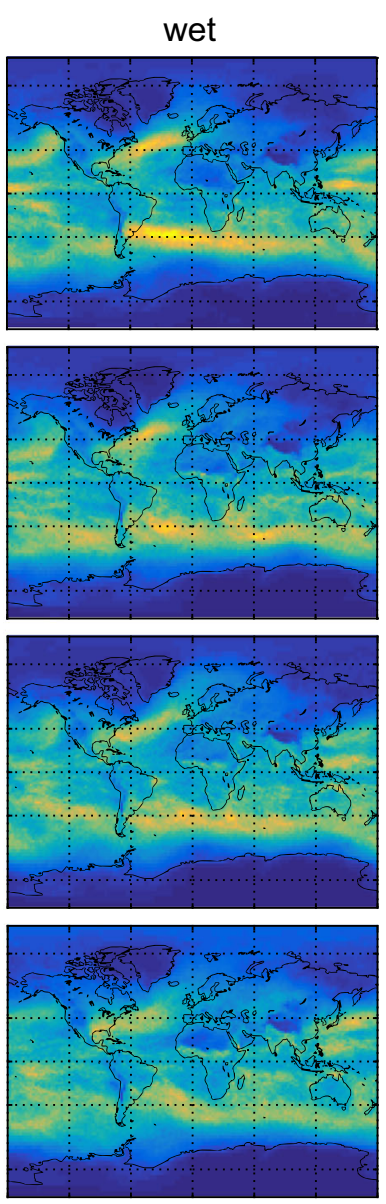

\section{RWPN $[\mathrm{mm} / \sqrt{\mathrm{h}}]$}

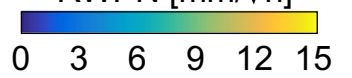

Fig. 2 Hydrostatic (top) and wet (bottom) yearly mean RWPN grids over 2012-2015

this reveals a drawback of the approach. Wet RWPN varies from $0.1 \mathrm{~mm} / \sqrt{ } \mathrm{h}$ over Antarctica and Greenland to $12.0 \mathrm{~mm} / \sqrt{ } \mathrm{h}$ over some ocean areas along $40^{\circ} \mathrm{N}$ and $40^{\circ} \mathrm{S}$ latitude. The mean wet RWPN value is $5.0 \mathrm{~mm} / \sqrt{ } \mathrm{h}$ with a standard deviation of $2.8 \mathrm{~mm} / \sqrt{ } \mathrm{h}$. Please note that wet RWPN values estimated with (3) and NWP data correspond well to the constraining applied by various researchers, already mentioned above. This confirms that the strategy of wet RWPN estimation based on Markov process theory is suitable for real-time GNSS ZTD estimation.

We noticed that grids are nearly identical year by year, with differences below $1 \mathrm{~mm} / \sqrt{ } \mathrm{h}$ for hydrostatic and wet grids. This means that a single RWPN grid can be implemented in a software in case only one static RWPN value per station is acceptable, without significant degradation of the grid accuracy. For further processing in the yearly variant, we used 2012 grids for the summer campaign and

2014 grids for the winter campaign, taking into account that those grids would have been available in case of realtime processing.

Seasonal mean RWPN grids are presented in Fig. 3. For clarity, we present only 4 grids from 2015, each grid shifted in time by 3 months, in order to present different seasons. Hydrostatic RWPN varies from $0.1 \mathrm{~mm} / \sqrt{\mathrm{h}}$ around poles to $5.4 \mathrm{~mm} / \sqrt{ } \mathrm{h}$ for ocean areas along $60^{\circ} \mathrm{S}$ latitude and the northern part of the North Atlantic Ocean. The mean hydrostatic RWPN value is $1.8 \mathrm{~mm} / \sqrt{ } \mathrm{h}$ with a standard deviation of $0.8 \mathrm{~mm} / \sqrt{ } \mathrm{h}$. Wet RWPN varies from $0.1 \mathrm{~mm} / \sqrt{ } \mathrm{h}$ over Antarctica and Greenland to $16.4 \mathrm{~mm} / \sqrt{ } \mathrm{h}$ over some ocean areas along $40^{\circ} \mathrm{N}$ and $40^{\circ} \mathrm{S}$ latitude. The mean wet RWPN value is $4.8 \mathrm{~mm} / \sqrt{ } \mathrm{h}$ with a standard deviation of $3.2 \mathrm{~mm} / \sqrt{ } \mathrm{h}$.

We noticed that both hydrostatic and wet RWPN vary not only geographically but also seasonally. The seasonal hydrostatic RWPN differences reach $2.9 \mathrm{~mm} / \sqrt{ }$ h over the 
north part of the North Atlantic Ocean, and $1.7 \mathrm{~mm} / \sqrt{\mathrm{h}}$ over the south part of the South Atlantic Ocean. The seasonal wet RWPN differences reach $7.3 \mathrm{~mm} / \sqrt{ } \mathrm{h}$ over the South Atlantic Ocean along $40^{\circ} \mathrm{S}$ latitude, $4.8 \mathrm{~mm} / \sqrt{ } \mathrm{h}$ between $45^{\circ} \mathrm{N}$ and $45^{\circ} \mathrm{S}$ and $2.0 \mathrm{~mm}$ for the remaining areas. The wet RWPN differences are significantly larger over ocean areas than over the continents.

\section{Case studies}

We investigated real-time ZTD estimates among variants for each station individually. We applied the simple ZTD quality filter by setting the threshold of $10 \mathrm{~mm}$ for the ZTD formal error in order to remove outliers and estimates during the solution initialization period. The best fixed variant was selected following the criteria of the smallest standard deviation of residuals between real-time and final solutions, while the percent of epochs with sufficient solution quality remains high. We found that the larger the wet RWPN, the lower is the availability of the solution. We noticed a station-specific bias between real-time and final solutions that is a well-known case in GNSS meteorology. Fortunately, for meteorological applications it can be corrected with monthly mean (Bennitt and Jupp 2012; Dousa et al. 2013). Moreover, this bias differs by less than $0.1 \mathrm{~mm}$ among all real-time variants, so it will not be a subject of further analysis. In general, we found two groups of stations: (1) in which yearly and seasonal variants are almost as good as the best fixed variant, while the dynamic variant is as good as or even better than the best fixed variant, (2) in which the results are ambiguous. Fortunately, only 6 from 20 stations can be assigned to the second group, namely: HOLM and NRIL (in the summer campaign only), BRAZ (in the winter campaign only), ABPO, ISPA and YSSK (in both campaigns).

A representative station in group 1 is station HERT (Fig. 4). In general, time series of estimated ZTD among variants fits well to the final solution. The best fixed solution is obtained for wet $\mathrm{RWPN}=4 \mathrm{~mm} / \sqrt{ } \mathrm{h}$ in the summer campaign and wet RWPN $=7 \mathrm{~mm} / \sqrt{ } \mathrm{h}$ in the winter campaign. In both campaigns, yearly and seasonal wet RWPNs differ $<1 \mathrm{~mm} / \sqrt{ } \mathrm{h}$ over the test periods; therefore, both variants result in very similar ZTD estimates. Both variants result in equally precise ZTD estimates as in the best fixed variant. The availability of solutions is also equally high, except for the seasonal variant in the winter campaign, when the availability is lower by $0.2 \%$. An improvement in real-time ZTD quality is obtained for the dynamic variant that reduces standard deviation of ZTD residuals by $18 \%$, keeping high availability of the accepted estimates. The improvement in realtime ZTD is significant in case of dynamic changes of tropospheric conditions, e.g., late evening of DoY 331, around noon of DoY 334 and 335, and evening of DoY 336 in 2015. In these periods, the dynamic wet RWPN setting is high, thus allowing the PPP filter to change the ZWD estimates rapidly. For the remaining periods, the dynamic RWPN is lower, so that ZWD estimates remain more stable over time, e.g., during DoY 330 and from the evening of DoY 335 to the evening of DoY 336 in 2015.
Fig. 4 Comparison of wet RWPN, ZTD time series, standard deviations of real-time ZTD residuals with respect to the final ZTD and solution availability among variants for station HERT
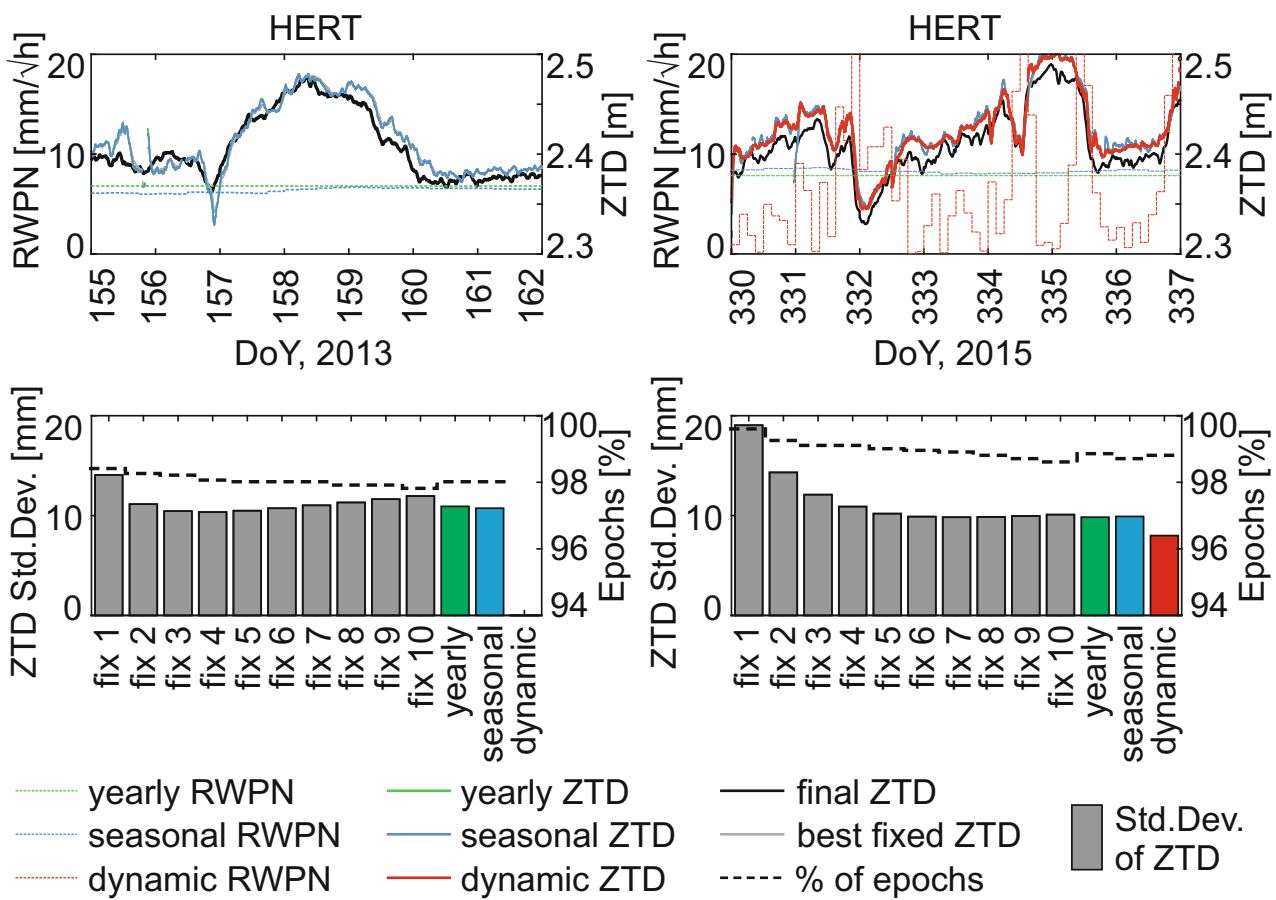
Fig. 5 Comparison of wet RWPN, ZTD time series, standard deviations of real-time ZTD residuals with respect to the final ZTD and solution availability among variants for station YSSK
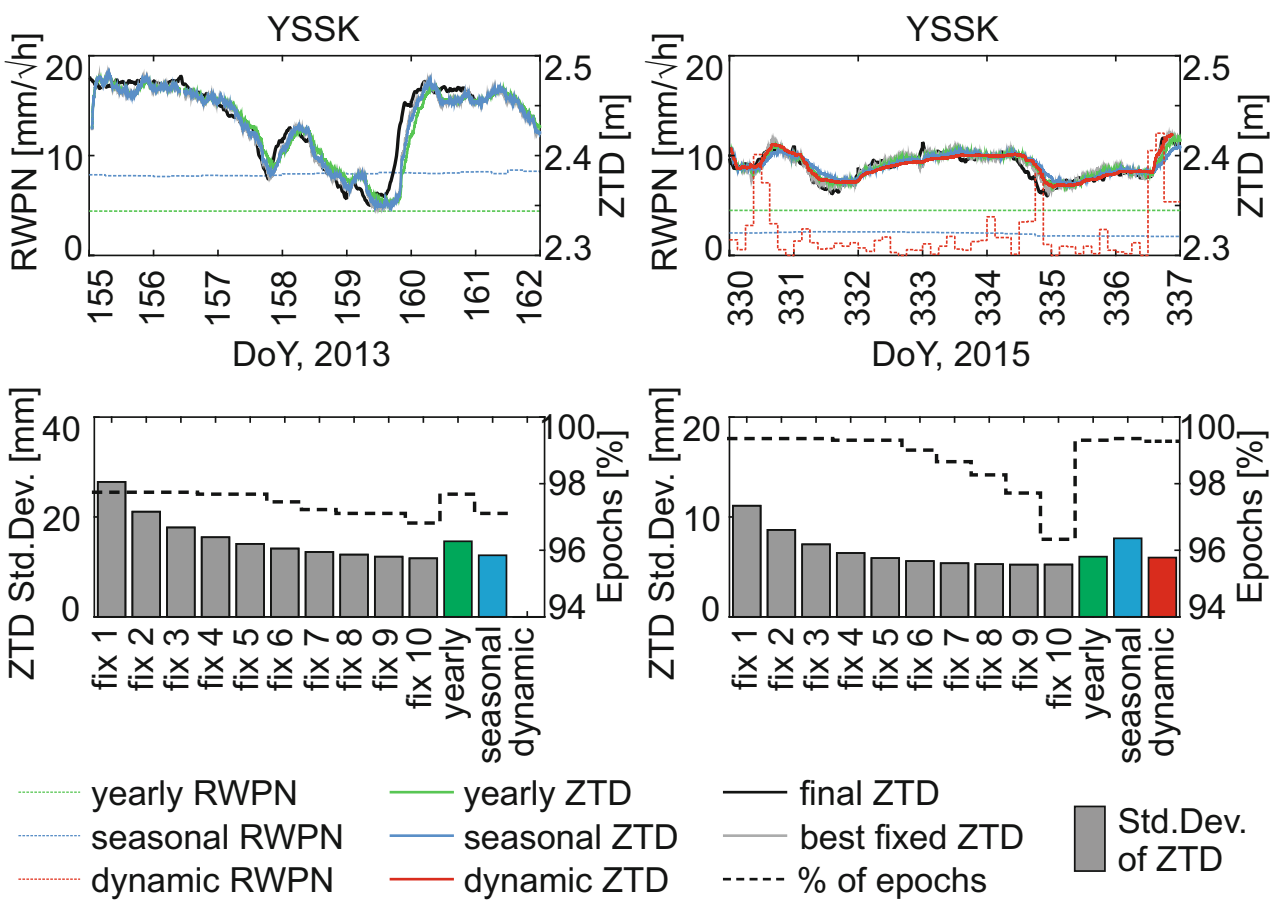

Station YSSK (Fig. 5) is a representative example of stations from the group 2. In this case, it is impossible to unambiguously indicate the best fixed wet RWPN, because the larger the RWPN, the smaller is the standard deviation; for RWPN larger than $5 \mathrm{~mm} / \sqrt{ } \mathrm{h}$, we observe a significant reduction in solution availability. A subjective selection of the best fixed variant will be RWPN $=5 \mathrm{~mm} / \sqrt{ } \mathrm{h}$ both for summer and winter campaign, as it keeps the high percentage of available solutions while the improvement in ZTD quality is not so significant for larger RWPN settings. The yearly variant returns very similar results to the best fixed variant in both campaigns. The seasonal wet RWPN differs significantly from the yearly wet RWPN in both campaigns; therefore, the quality and availability of the results vary among campaigns and do not correspond to the best fixed solution. The dynamic variant returns results that are comparable with the yearly approach, in the sense of low standard deviation of residuals and high availability of results. However, the time series of yearly and dynamic variant varies. The dynamic time series is much smoother due to very low dynamic RWPN setting for most of the time.

\section{Comparison against global RWPN}

We compared best fixed, yearly, mean seasonal and mean dynamic wet RWPN values, as well as the availability and quality of estimated ZTD among stations for both campaigns. The comparison of wet RWPN among variants is presented in Fig. 6. For the best fixed RWPN value, the

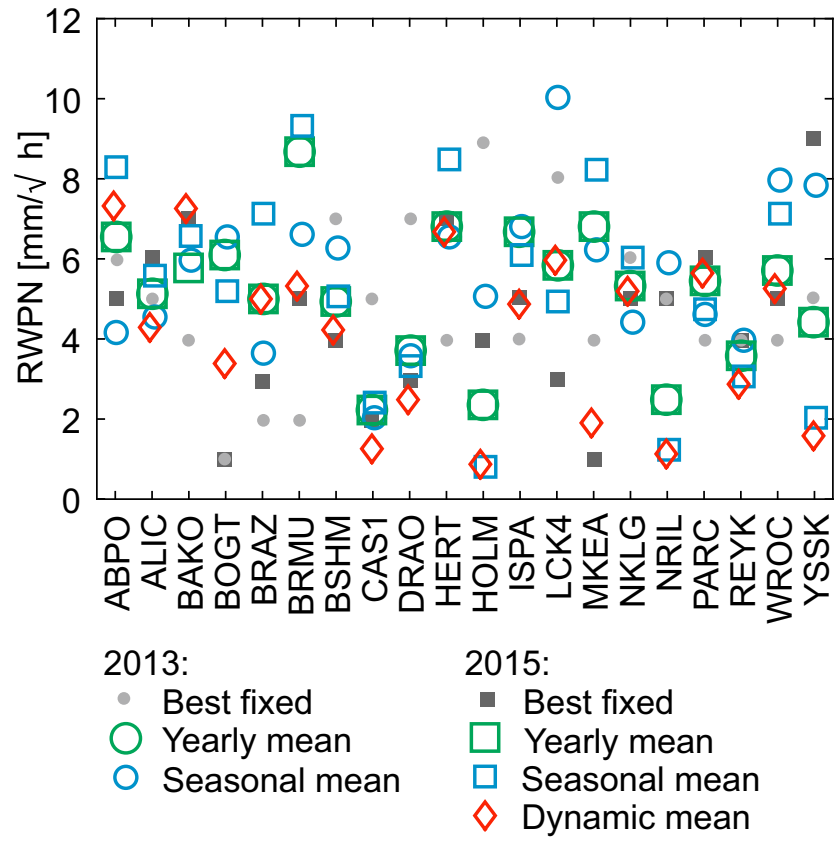

Fig. 6 Comparison of wet RWPN among variants and campaigns

differences between campaigns are usually about $2-3 \mathrm{~mm} / \sqrt{ } \mathrm{h}$. The yearly RWPN often agreed with the best fixed RWPN at the level of $2 \mathrm{~mm} / \sqrt{ } \mathrm{h}$, but for some stations the disagreement is strong, e.g., stations BOGT, LCK4, NRIL and YSSK. The seasonal RWPN differs from the corresponding yearly RWPN also by a few $\mathrm{mm} / \sqrt{\mathrm{h}}$, and the differences in seasonal RWPN between campaigns range from 0 to $5.8 \mathrm{~mm} / \sqrt{ } \mathrm{h}$. The mean dynamic RWPN usually 
corresponds well to the yearly RWPN, with differences from 0 to $3 \mathrm{~mm} / \sqrt{ } \mathrm{h}$. The RWPN in all variants varies significantly among stations, and we did not find any relation between the best fixed wet RWPN value and station location or its height. It means that, as expected, the best wet RWPN value is both location and time specific because it depends on the atmospheric conditions.

We also compared variants in the sense of availability of accepted ZWD estimates (Fig. 7). We found that availability is over $95 \%$ for 17 stations in the summer campaign (the worst stations are BOGT, LCK4 and MKEA) and 19 stations in the winter campaign (the worst station is MKEA). Again, we noticed the decrease in availability with an increase in wet RWPN in the fixed variant. The yearly variant provides similar ZWD estimates availability if $\mathrm{RWPN}=6 \mathrm{~mm} / \sqrt{\mathrm{h}}$ in the summer campaign and $\mathrm{RWPN}=7 \mathrm{~mm} / \sqrt{\mathrm{h}}$ in the winter campaign are applied to all stations. The seasonal approach is, in general, slightly worse than the yearly approach. In the dynamic variant, the availability for station MKEA increased significantly to $76 \%$, compared to $38 \%$ in the yearly variant. For few stations, the availability is slightly decreased, by less than $2 \%$ compared with the yearly variant.

We also compared variants in the sense of the quality of estimated real-time ZTD, by analyzing the standard deviation of ZTD residuals with respect to the ZTD final estimates (Fig. 8). We found the best empirical global value of wet RWPN is $8 \mathrm{~mm} / \sqrt{ } \mathrm{h}$ in the summer campaign and $6 \mathrm{~mm} / \sqrt{\mathrm{h}}$ in the winter campaign. In the summer campaign, for fixed wet RWPN $>5 \mathrm{~mm} / \sqrt{ } \mathrm{h}$, as well as in the yearly and seasonal variants, the average standard deviation is around $10 \mathrm{~mm}$ and does not exceed $20 \mathrm{~mm}$ for any station. Compared to the best fixed variant, the yearly and seasonal variants resulted in a slightly higher and slightly lower standard deviation, respectively. In the winter campaign for global wet RWPN $=6 \mathrm{~mm} / \sqrt{ } \mathrm{h}$, the standard deviation of residuals varies from 3.8 to $16.8 \mathrm{~mm}$ with a mean value of $9.7 \mathrm{~mm}$. The yearly variant resulted in a slightly lower standard deviation compared to the best fixed variant, while the seasonal variant resulted in a higher standard deviation than both the yearly and best fixed variants. The dynamic variant significantly improves the accuracy, and the standard deviation of residuals varies from 4.2 to $14.7 \mathrm{~mm}$ with a mean value of $9.2 \mathrm{~mm}$.

\section{Comparison against station-specific RWPN}

Finally, we checked if any of the proposed variants can provide results of the same quality as if the fixed RWPN is adjusted empirically for each station and each campaign individually. The results for the summer and winter campaign are presented in Tables 1 and 2, respectively. The results presented in the individually
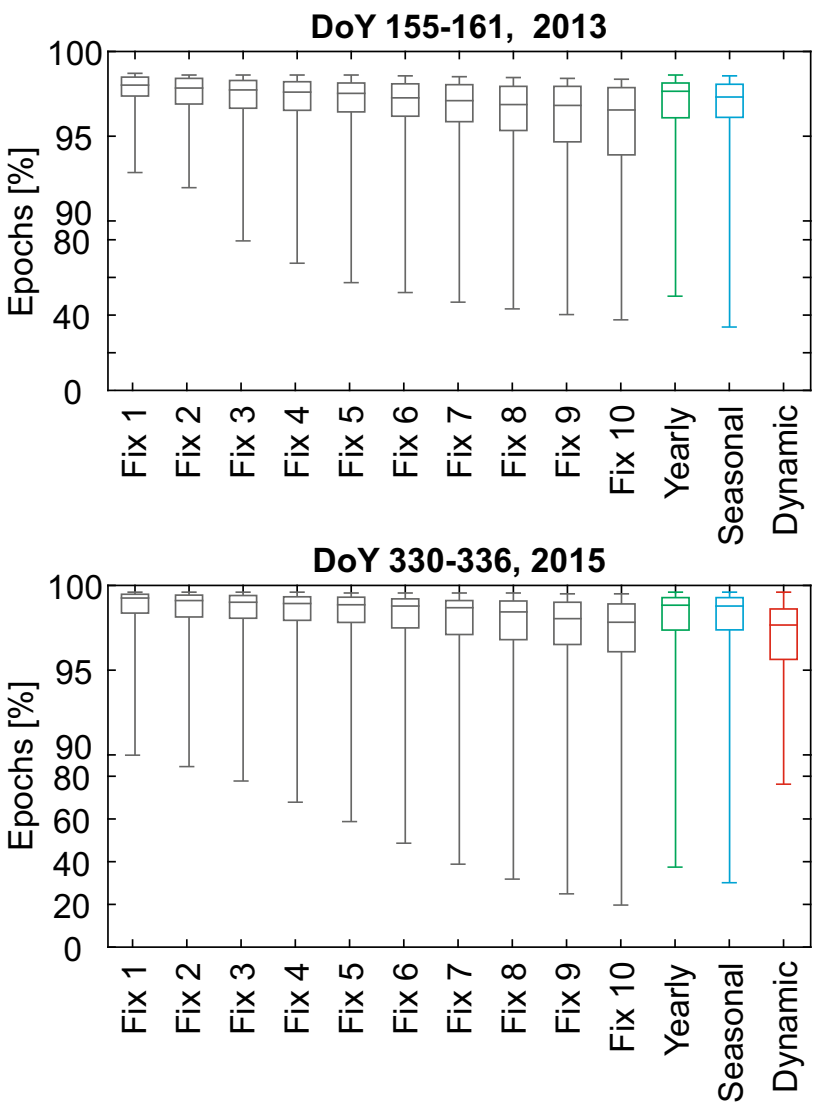

Fig. 7 Availability of epochs with estimated real-time ZTD. Note different scales of the vertical axis between ranges $0-90 \%$ and $90-100 \%$

fixed row correspond to the case when an initial empirical test is performed for each station individually. These results should be considered as target values, because better results cannot be obtained with any other fixed RWPN value. If any of the proposed variants can eliminate the requirement of an initial empirical test, the results should be close to the target values. It is important to note that it is not possible to perform such an ideal empirical test in real-time processing, because RWPN can only be empirically adjusted to a past time series, so it may not be suitable for the current atmospheric conditions.

We found that the yearly variant is, in general, only slightly worse than the empirical testing, providing very similar availability of data, while the standard deviation of residuals is larger by $0.8 \mathrm{~mm}$ both in the summer and winter campaigns. There is only one station, namely MKEA, for which the results in the winter campaign are degraded (from 14.2 to $17.7 \mathrm{~mm}$ ) and of lower availability (by $51 \%$ ). For the seasonal variant, the availability of solution is lower than in the yearly variant, and the accuracy is comparable or even worse than in the yearly variant. The dynamic variant provides significantly better results 

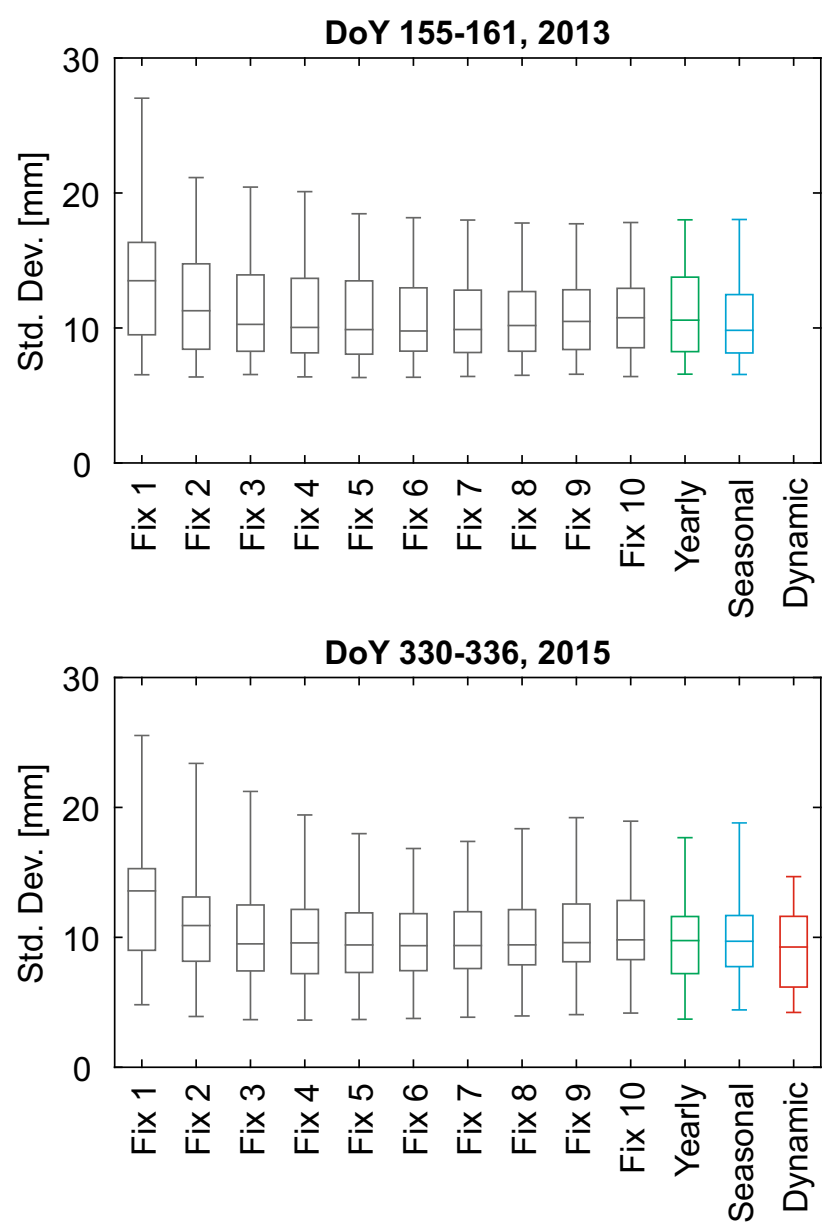

Fig. 8 Standard deviation of real-time ZTD residuals with respect to the final ZTD

than the yearly variant, increasing the availability of results on average from 95.2 to $96.9 \%$ and reducing the average standard deviation from 9.7 to $9.2 \mathrm{~mm}$.

\section{Conclusions}

We have shown that the optimum ZWD constraints in realtime GNSS processing, modeled as a random walk process, should be time and location specific. This means that a single random walk processing noise (RWPN) value should not be applied globally to all stations, because it may lead to significant degradation of solution quality. We performed empirical tests for each station and each campaign individually in order to get reference values of wet RWPN, for which the standard deviation with respect to the final ZTD estimates is low, and the availability of the real-time solution is high. It is important to note that empirical testing was performed in post-processing mode, so wet RWPN values were adjusted to the current set of data, which is not the case in real-time processing.

In order to eliminate prior empirical testing, we propose 3 strategies to estimate RWPN that use Gauss-Markov process theory and NWP data of limited temporal and spatial resolution. We compared the quality of the results obtained with the proposed strategies against the results obtained with the empirical testing. In general, this comparison showed that with yearly wet RWPN grids we can reconstruct and with a mean error of $1 \mathrm{~mm} / \sqrt{\mathrm{h}}$, the wet RWPN value obtained from empirical testing. Because yearly grids are very similar year by year, it is sufficient to implement only a single yearly grid in a software as a look up table to define the optimum wet RWPN value for any station located worldwide. However, it is recommended to make an update every few years. Such a grid is a novelty product for the GNSS community that eliminates the timeconsuming and period-sensitive empirical testing. A further improvement is foreseen in an ECMWF replacement with a NWP model of higher spatial and temporal resolution, which is a goal of our future studies. Moreover, a longer
Table 1 Wet RWPN range, available epochs and standard deviations among processing variants, DoY 155-161, 2013

\begin{tabular}{|c|c|c|c|c|c|c|c|c|}
\hline & \multicolumn{2}{|c|}{ RWPN $[\mathrm{mm} / \sqrt{ } / \mathrm{h}]$} & \multicolumn{3}{|c|}{ Epochs [\%] } & \multicolumn{3}{|c|}{$\mathrm{SD}[\mathrm{mm}]$} \\
\hline & Min & Max & Avg & Min & Max & Avg & Min & $\operatorname{Max}$ \\
\hline Indiv. fixed & 2.0 & 9.0 & 93.7 & 60.7 & 98.2 & 10.3 & 6.3 & 17.4 \\
\hline Yearly & 2.2 & 8.6 & 93.4 & 60.7 & 98.3 & 11.1 & 6.6 & 18.0 \\
\hline Seasonal & 1.8 & 11.2 & 92.5 & 41.0 & 98.2 & 10.9 & 6.6 & 18.0 \\
\hline
\end{tabular}

\begin{tabular}{|c|c|c|c|c|c|c|c|c|}
\hline & \multicolumn{2}{|c|}{$\mathrm{RWPN}[\mathrm{mm} / \sqrt{\mathrm{h}}]$} & \multicolumn{3}{|c|}{ Epochs [\%] } & \multicolumn{3}{|c|}{$\mathrm{SD}[\mathrm{mm}]$} \\
\hline & Min & Max & Avg & Min & Max & Avg & Min & Max \\
\hline Indiv. fixed & 1.0 & 9.0 & 97.5 & 87.7 & 99.5 & 8.9 & 3.6 & 14.2 \\
\hline Yearly & 2.2 & 9.3 & 95.2 & 36.4 & 99.5 & 9.7 & 3.7 & 17.7 \\
\hline Seasonal & 0.8 & 10.1 & 94.8 & 30.4 & 99.5 & 9.8 & 4.4 & 18.8 \\
\hline Dynamic & 0.0 & 45.3 & 96.9 & 73.2 & 99.5 & 9.2 & 4.2 & 14.7 \\
\hline
\end{tabular}

Table 2 Wet RWPN range, available epochs and standard deviations among processing variants, DoY 330-336, 2015 
time period should be investigated in order to determine how often (if at all) such a grid should be updated.

The seasonal wet RWPN grids lead to slightly worse results than the yearly grids. Therefore, and due to the increased complexity of seasonal grid implementation, this strategy is not recommended. The degradation of the realtime ZTD quality in the seasonal variant can be explained by the incorrect assumption that seasonal tropospheric conditions repeat every year.

A superior result was obtained with the third proposed strategy, namely the dynamic strategy, which is based on regular ray-tracing through a shortest available forecast from a NWP model. The results are almost as good as those from the post-processing empirical testing. The advantage of this approach is that the wet RWPN is regularly adjusted to the current tropospheric conditions. Its value remains low, when ZTD is stable over time, and rises when a rapid change of ZTD is expected. The drawback of this approach is high computational power required to perform NWP raytracing on a regular basis for each station in the processing. It should be verified in the near future, if a NWP model of higher spatial and temporal resolution can further improve real-time ZTD estimates.

Acknowledgements This work has been supported by the Ministry of Science and Higher Education research Project No 2014/15/B/ ST10/00084, COST Action ES1206 GNSS4SWEC (www.gnss4swec. knmi.nl), and the Wroclaw Center of Networking and Supercomputing (http://www.wcss.wroc.pl/) computational Grant using MATLAB Software License No: 101979. The authors gratefully acknowledge the International GNSS Service (IGS) for providing real-time streams and final tropospheric products, the Bundesamt für Kartographie und Geodäsie (BKG) for providing the open-source BNC software, and ECMWF and NOAA for providing NWP models.

Open Access This article is distributed under the terms of the Creative Commons Attribution 4.0 International License (http://crea tivecommons.org/licenses/by/4.0/), which permits unrestricted use, distribution, and reproduction in any medium, provided you give appropriate credit to the original author(s) and the source, provide a link to the Creative Commons license, and indicate if changes were made.

\section{References}

Ahmed F, Vaclavovic P, Teferle FN, Dousa J, Bingley R, Laurichesse D (2016) Comparative analysis of real-time precise point positioning zenith total delay estimates. GPS Solut 20(187):199. doi:10.1007/s10291-014-0427-z

Bennitt GV, Jupp A (2012) Operational assimilation of GPS zenith total delay observations into the met office numerical weather prediction models. Mon Weather Rev 140(8):2706-2719

Bevis M, Businger S, Chiswell S, Herring TA, Anthes RA, Rocken C, Ware RH (1992) GPS meteorology: remote sensing of atmospheric water vapor using the global positioning system. J Geophys Res 97(D14):15787-15801

Bharucha-Reid AT (1960) Elements of the theory of Markov processes and their applications. McGraw-Hill, New York
Bianchi CE, Mendoza LPO, Fernandez LI, Moitano JF (2016) Multiyear GNSS monitoring of atmospheric IWV over Central and South America for climate studies. Ann Geo 34(7):623-639. doi:10.5194/angeo-34-623-2016

Böhm J, Kouba J, Schuh H (2009) Forecast vienna mapping functions 1 for real-time analysis of space geodetic observations. J Geod 86(5):397-401

Caissy M, Agrotis L, Weber G, Hernandez-Pajares M, Hugentobler U (2012) Coming soon: the international GNSS real-time service. GPS World 23(6):52-58

Dach R, Lutz S, Walser P, Fridez P (2015) Bernese GNSS Software Version 5.2. User manual, Astronomical Institute, University of Bern, Bern Open Publishing. doi:10.7892/boris.72297. ISBN: 978-3-906813-05-9

Davis JL, Herring TA, Shapiro II, Rogers AEE, Elgered G (1985) Geodesy by radio interferometry: effects of atmospheric modeling errors on estimates of baseline length. Radio Sci 20(6): 1593-1607

de Oliveira PS, Morel L, Fund F, Legros R, Monico JFG, Durand S, Durand F (2016) Modeling tropospheric wet delays with dense and sparse network configurations for PPP-RTK. GPS Solut (online). doi:10.1007/s10291-016-0518-0

Dousa J (2010) Precise near real-time GNSS analyses at Geodetic observatory Pecný: precise orbit determination and water vapor monitoring. Acta Geodyn Geomater 7(1):1-11

Dousa J, Bennitt GV (2013) Estimation and evaluation of hourly updated global GPS zenith total delays over ten months. GPS Solut 17(453):464

Dousa J, Vaclavovic P, Gyori G, Kostelecky J (2013) Development of real-time GNSS ZTD products. Adv Space Res 53:13471358

Elgered G, Plag HP, Van der Marel H, Barlag S, Nash J (2005) COST action 716: exploitation of ground-based GPS for operational numerical weather prediction and climate applications. Official Publications of the European Communities, Luxembourg

Guerova G, Jones J, Dousa J, Dick G, De Haan S, Pottiaux E, Bock O, Pacione R, Elgered G, Vedel H, Bender M (2016) Review of the state-of-the-art and future prospects of the ground-based GNSS meteorology in Europe. Atmos Meas Tech Discuss. doi:10.5194/ amt-2016-125

Hadas T (2015) GNSS-warp software for real-time precise point positioning. Artif Satell 50(2):59-76

Hadas T, Kaplon J, Bosy J, Sierny J, Wilgan K (2013) Near-real-time regional troposphere models for the GNSS precise point positioning technique. Meas Sci Technol 24(5):055003-055014

Hernández-Pajares M, Juan JM, Sanz J, Colombo OL, Van der Marel H (2001) A new strategy for real-time integrated water vapor determination in WADGPS Networks. Geophys Res Lett 28(17):3267-3270

Hopfield HS (1969) Two-quartic tropospheric refractivity profile for correcting satellite data. J Geophys Res 74:4487-4499

Karabatic A, Weber R, Haiden T (2011) Near real-time estimation of tropospheric water vapor content from ground based GNSS data and its potential contribution to weather now-casting in Austria. Adv Space Res 47:1691-1703

Kouba J (2015) A guide to Using the IGS Products. Online: http://kb. igs.org/hc/en-us/articles/201271873-A-Guide-to-Using-the-IGSProducts. Accessed 17 Aug 2016

Kouba J, Heroux P (2001) Precise point positioning using IGS orbit and clock products. GPS Solut 5(2):12-28

Lagler K, Schindelegger M, Böhm J, Krásná H, Nilsson T (2013) GPT2: empirical slant delay model for radio space geodetic techniques. Geophys Res Lett 40:1069-1073. doi:10.1002/grl. 50288

Leandro RF, Santos MC, Langley RB (2006) UNB neutral atmosphere models: development and performance. In: Proceedings 
of ION NTM 2006, Institute of Navigation, Monterey, CA, Jan 18-20, pp 564-573

Li X, Dick G, Ge M, Heise S, Wickert J, Bender M (2014) Real-time GPS sensing of atmospheric water vapor: precise point positioning with orbit, clock and phase delay corrections. Geophys Res Lett 41(10):3615-3621. doi:10.1002/2013GL058721

Li X, Dick G, Lu C, Ge M, Nilsson T, Ning T, Wickert J, Schuh H (2015) Multi-GNSS meteorology: real-time retrieving of atmospheric water vapor from BeiDou, Galileo, GLONASS, and GPS observations. IEEE Trans Geosci Remote Sens. doi:10.1109/ TGRS.2015.2438395

Lu C, Li X, Nilson T, Ning T, Heinkelmann R, Ge M, Glaser S, Schuh H (2015) Real-time retrieval of precipitable water vapor from GPS and BeiDou observations. J Geod 89(9):843-856

Mendes VB (1999) Modeling the neutral-atmospheric propagation delay in radiometric space techiniques. $\mathrm{PhD}$ dissertation, University of New Brunswick

Niell AE (1996) Global mapping functions for the atmosphere delay at radio wavelengths. J Geophys Res 101:3227-3246

Ning T (2012) GPS meteorology: with focus on climate applications. PhD thesis, Chalmers University of Technology. ISBN 978-917385-675-1

Pacione R, Vespe F (2008) Comparative studies for the assessment of the quality of near-real-time GPS-derived atmospheric parameters. J Atmos Ocean Tech 25:701-714

Pacione R, Vespe F, Pace B (2009) Near Real-Time GPS Zenith Total Delay validation at E-GVAP Super Sites. Bollettino Di Geodesia E Scienze Affini 1

Rocken C, Sokolovskiy S, Johnson JM, Hunt D (2001) Improved mapping of tropospheric delays. J Atmos Ocean Tech 18(7):1205-1213

Rohm W, Yang Y, Biadeglgne B, Zhang K, Le Marshall J (2014) Ground-based GNSS ZTD/IWV estimation system for numerical weather prediction in challenging weather conditions. Atmos Res 138:414-426. doi:10.1016/j.atmosres.2013.11.026

Rüeger JM (2002) Refractive index formulae for radio waves. Integration of techniques and corrections to achieve accurate engineering. In: Proceedings of XXII FIG International Congress, Washington, DC, USA, Apr 19-26, pp 1-13

Saastamoinen J (1972) Contributions to the theory of atmospheric refraction. Bull Géod 105:13-34

Satirapod C, Anonglekha S, Coy Y, Lee H (2011) Performance assessment of GPS-sensed precipitable water vapor using IGS ultra-rapid orbits: a preliminary study in Thailand. Eng J 15:1-8

Shi J, Xu C, Li Y, Gao Y (2015) Impacts of real-time satellite clock errors on GPS precise point positioning-based troposphere zenith delay estimation. J Geod 89:747-756

US Standard Atmosphere (1976) NASA TM-X 74335. National Oceanic and Atmospheric Administration. National Aeronautics and Space Administration and United States Air Force

Vedel H, Mogensen K, Huang XY (2001) Calculation of zenith delays from meteorological data comparison of NWP model, radiosonde and GPS delays. Phys Chem Earth 26:497-502. doi:10. 1016/S1464-1895(01)00091-6

Vedel H, De Haan S, Jones J, Bennitt G, Offiler D (2013) E-GVAP third phase. Geophys Res Abstr 15:EGU2013-10919

Wilgan K (2015) Zenith total delay short-term statistical forecasts for GNSS precise point positioning. Acta Geodyn Geomater 12(4):335-343

Yuan Y, Zhang K, Rohm W, Choy S, Norman R, Wang SC (2014) Real-time retrieval of precipitable water vapor from GPS precise point positioning. J Geophys Res Atmos 119(6):10044-10057. doi:10.1002/2014JD021486

Zhu Q, Zhao Z, Lin L, Wu Z (2010) accuracy improvement of zenith tropospheric delay estimation based on GPS precise point positioning algorithm. Geo Spat Inf Sci 13(4):306-310

Zumberge JF, Heflin MB, Jefferson DC, Watkins MM, Webb FH (1997) Precise point positioning for the efficient and robust analysis of GPS data from large networks. J Geophys Res 102(B3):5005-5018. doi:10.1029/96JB03860

Zus F, Dick G, Dousa J, Heise S, Wickert J (2014) The rapid and precise computation of GPS slant total delays and mapping factors utilizing a numerical weather model. Radio Sci 49(3):207-216

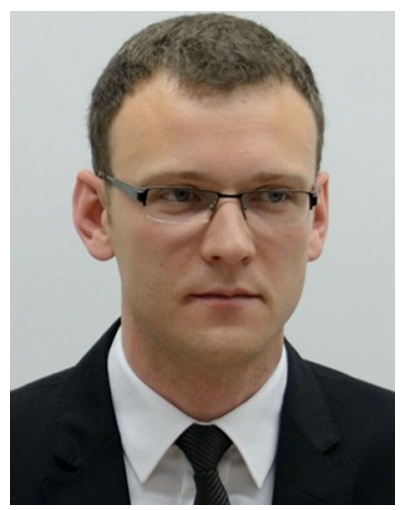

Tomasz Hadas received his $\mathrm{PhD}$ in satellite geodesy in 2015. He is an assistant professor at the Institute of Geodesy and Geoinformatics, Wroclaw University of Environmental and Life Sciences, Poland. He is working on development of GNSS real-time precise positioning algorithms, troposphere modeling in real-time and application of atmosphere models into GNSS positioning.

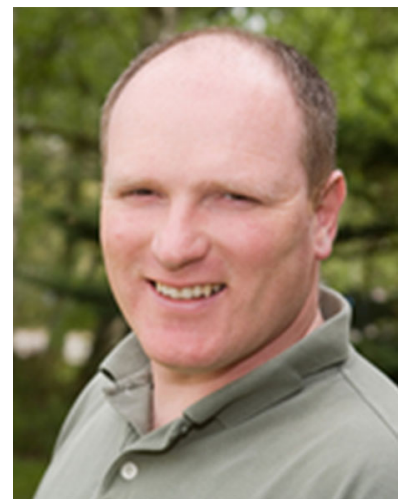

modeling of time series.

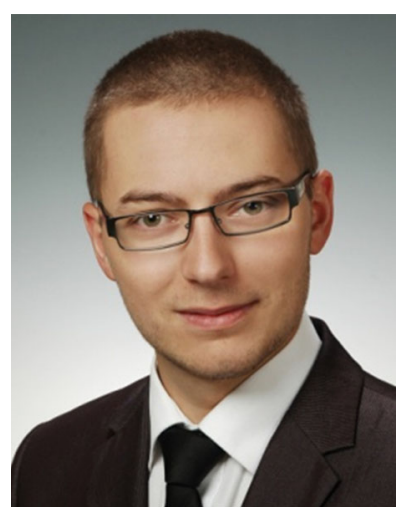

Felix Norman Teferle is Professor of Geodesy at the University of Luxembourg, Luxembourg. His research focuses on improving GNSS processing strategies and bias models for high-precision positioning while applying the technique to a range of geodetic and geophysical problems. Particular areas of interest are the monitoring of land movements in relation to sea level studies, the estimation of atmospheric water vapor and the stochastic

Kamil Kazmierski graduated from Wroclaw University of Environmental and Life Sciences in 2014 obtaining a Master Degree in Geodesy and Cartography. He is a $\mathrm{PhD}$ student at the Institute of Geodesy and Geoinformatics, Wroclaw University of Environmental and Life Sciences, Poland. He is working on development of Multi-GNSS real-time precise positioning algorithms. 


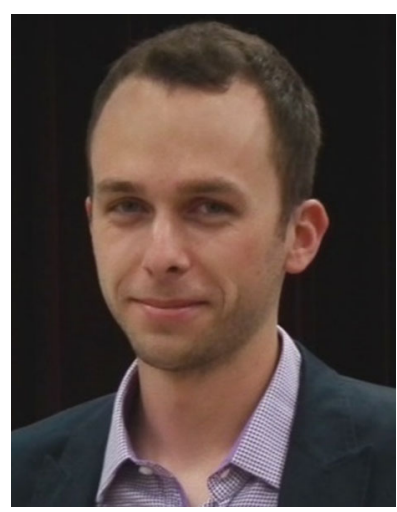

Pawel Hordyniec graduated from Wroclaw University of Environmental and Life Sciences in 2013 with a Master Degree in Geodesy and Cartography. He is a $\mathrm{PhD}$ student and a research assistant at the Institute of Geodesy and Geoinformatics, Wroclaw University of Environmental and Life Sciences, Poland. His main field of research is GPS radio occultation technique and signal raytracing for ground- and spacebased GNSS applications.

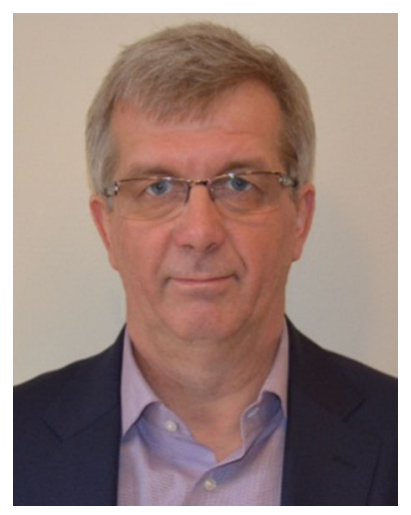

Jaroslaw Bosy has been a Professor at the Institute of Geodesy and Geoinformatics, Wroclaw University of Environmental and Life Sciences, Poland since 2008. He was awarded a PhD in Geodesy and Cartography in 1996 and habilitation in 2006 from Faculty of Mining Surveying and Environmental Engineering of AGH University of Science and Technology, Krakow, Poland. His research are concentrated on reference frames realization in global, regional and local scale using GNSS techniques to derive information about the state of the atmosphere and application of GNSS technique in geodesy and geodynamics. 